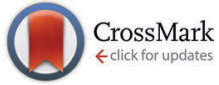

Cite this: Phys. Chem. Chem. Phys., 2014, 16, 26617

Received 16th May 2014, Accepted 10th September 2014

DOI: $10.1039 / \mathrm{c} 4 \mathrm{cp} 02139 \mathrm{~h}$

www.rsc.org/pccp

\section{Highly regioselective hydride transfer, oxidative dehydrogenation, and hydrogen-atom abstraction in the thermal gas-phase chemistry of $[\mathrm{Zn}(\mathrm{OH})]^{+} / \mathrm{C}_{3} \mathrm{H}_{8} \dagger^{+}$}

\author{
Xiao-Nan Wu, Hai-Tao Zhao, Jilai Li, Maria Schlangen* and Helmut Schwarz*
}

\begin{abstract}
The thermal reactions of $[\mathrm{Zn}(\mathrm{OH})]^{+}$with $\mathrm{C}_{3} \mathrm{H}_{8}$ have been studied by means of gas-phase experiments and computational investigation. Two types of $\mathrm{C}-\mathrm{H}$ bond activation are observed in the experiment, and pertinent mechanistic features include inter alia: (i) the metal center of $[\mathrm{Zn}(\mathrm{OH})]^{+}$serves as active site in the hydride transfer to generate $\left[i-\mathrm{C}_{3} \mathrm{H}_{7}\right]^{+}$as major product, (ii) generally, a high regioselectivity is accompanied by remarkable chemoselectivity: for example, the activation of a methyl $\mathrm{C}-\mathrm{H}$ bond results mainly in the formation of water and $\left[\mathrm{Zn}\left(\mathrm{C}_{3}, \mathrm{H}_{7}\right)\right]^{+}$. According to computational work, this ionic product corresponds to $\left[\mathrm{HZn}\left(\mathrm{CH}_{3} \mathrm{CH}=\mathrm{CH}_{2}\right)\right]^{+}$. Attack of the zinc center at a secondary $\mathrm{C}-\mathrm{H}$ bond leads preferentially to hydride transfer, thus giving rise to the generation of $\left[i-\mathrm{C}_{3} \mathrm{H}_{7}\right]^{+}$; (iii) upon oxidative dehydrogenation $(\mathrm{ODH})$, liberation of $\mathrm{CH}_{3} \mathrm{CH}_{2}=\mathrm{CH}_{2}$ occurs to produce $\left[\mathrm{HZn}\left(\mathrm{H}_{2} \mathrm{O}\right)\right]^{+}$. Both, $\mathrm{ODH}$ as well as $\mathrm{H}_{2} \mathrm{O}$ loss proceed through the same intermediate which is characterized by the fact that a methylene hydrogen atom from the substrate is transferred to the zinc and one hydrogen atom from the methyl group to the $\mathrm{OH}$ group of $[\mathrm{Zn}(\mathrm{OH})]^{+}$. The combined experimental/computational gas-phase study of $\mathrm{C}-\mathrm{H}$ bond activation by zinc hydroxide provides mechanistic insight into related zinc-catalyzed large-scale processes and identifies the crucial role that the Lewis-acid character of zinc plays.
\end{abstract}

\section{Introduction}

Enhancing the efficiency for the selective activation of carbonhydrogen bonds is linked to the success in generating new or improving existing catalysts. ${ }^{1-3}$ To this end, great efforts have been undertaken to reveal the mechanisms of bond activation processes at a molecular level. ${ }^{3-8}$ Among the various catalysts so far applied in industry, quite a few employ transition metals. Zinc-based catalysts are also in use, for example in the oxidative conversion of $\mathrm{CH}_{4}, \mathrm{C}_{2} \mathrm{H}_{6}$ and $\mathrm{C}_{3} \mathrm{H}_{8} \cdot{ }^{9}$ Further, zinc-doped zeolites are known to be effective catalysts for promoting dehydrogenation and aromatization of light alkanes, and $\mathrm{Zn}$ species including $[\mathrm{Zn}(\mathrm{OH})]^{+}$are believed to play a key role in these mechanistically rather complex transformations. ${ }^{10-12}$ Also, pure or Li doped zinc oxides act as catalyst for the $\mathrm{C}-\mathrm{H}$ bond activation of light alkanes, e.g. in the oxidative coupling of methane or the oxidative dehydrogenation of ethane and propane. ${ }^{13}$ While in all these reactions, $\mathrm{Zn}$ species are considered as the active ingredients, the reaction mechanisms as well as the precise

Institut für Chemie, Technische Universität Berlin, Straße des 17. Juni 135, 10623, Berlin.E-mail: Maria.Schlangen@mail.chem.tu-berlin.de,

Helmut.Schwarz@tu-berlin.de

$\dagger$ Dedicated to Professor A. W. Castleman, Jr., in recognition of his inspiring work on gas-phase catalysis.

‡ Electronic supplementary information (ESI) available. See DOI: 10.1039/c4cp02139h structure and exact composition of the active sites of the catalysts are still under debate. ${ }^{12,14,15}$ In this respect, gas-phase experiments have proven useful because they provide in an unperturbed way rather detailed insight into the elementary steps of numerous transformations mediated by zinc-containing catalysts. ${ }^{16-18}$

There have been several experimental and theoretical studies on the gas-phase reactions with various zinc species. ${ }^{19-23}$ As shown by Georgiadis and Armentrout, $\mathrm{C}-\mathrm{C}$ bond cleavage of alkanes can be achieved by atomic $[\mathrm{Zn}]^{+} \cdot{ }^{24}$ Further, the interaction of neutral [ZnO] with $\mathrm{CH}_{4}$ has been investigated by theoretical methods, and possible pathways yielding syngas, $\mathrm{CH}_{2} \mathrm{O}$, and $\mathrm{CH}_{3} \mathrm{OH}$, respectively, have been identified. ${ }^{25}$ Kretschmer et al. reported $\mathrm{N}-\mathrm{H}$ bond activation of $\mathrm{NH}_{3}$ by $[\mathrm{Zn}(\mathrm{OH})]^{+},{ }^{17}$ and $\mathrm{CO}_{2}$ activation has been brought about in the reaction of $\left[\mathrm{L}_{n} \mathrm{Zn}(\mathrm{OH})\right]^{+}$ ( $\mathrm{L}=$ imidazole and pyridine; $n=1,2$ ) in analogy with the Lipscomb mechanism for carbonic anhydrase. ${ }^{18}$ However, the activation of $\mathrm{C}-\mathrm{H}$ bonds of light alkanes with zinc hydroxide is much less investigated. This is rather surprising given the fact that welldesigned gas-phase processes of transition-metal fragments using advanced mass-spectrometric techniques in conjunction with theoretical studies have greatly helped in uncovering mechanistic aspects underlying $\mathrm{C}-\mathrm{H}$ bond activation. ${ }^{3,5,7,8,26-33}$

Herein we present a combined experimental/theoretical investigation of the gas-phase reactions of cationic zinc hydroxide 
with alkanes. While $[\mathrm{Zn}(\mathrm{OH})]^{+}$does not activate methane and ethane, mechanistically rather remarkable processes with propane are observed. As will be shown, studying the mechanistic aspects of $\mathrm{C}-\mathrm{H}$ bond activation by zinc species proves helpful to understand the role of zinc in catalysis in a broader context.

\section{Methods}

Experiments were performed with a VG BIO-Q mass spectrometer of QHQ configuration (Q: quadrupole, H: hexapole) equipped with an ESI source, as described previously in detail. ${ }^{34}$ To this end, Q(1) is used for mass-selection of the ion of interest and then, in the rf-only hexapole, the ion/molecule reactions are conducted. Ionic products are analyzed by scanning $\mathrm{Q}(2)$. Further, for ESI, millimolar solutions of $\mathrm{Zn}\left(\mathrm{NO}_{3}\right)$ in pure methanol were introduced through a fused-silica capillary to the ESI source by a syringe pump (ca. $4 \mu \mathrm{L} \min ^{-1}$ ) to produce the $[\mathrm{Zn}(\mathrm{OH})]^{+}$cations. Nitrogen was used as a nebulizing and drying gas at a source temperature of $80^{\circ} \mathrm{C}$. Maximal yields of the desired complexes were achieved by adjusting the cone voltage $\left(U_{\mathrm{c}}\right)$ to $80 \mathrm{~V} ; U_{\mathrm{c}}$ determines the degree of collisional activation of the incident ions in the transfer from the ESI source to the mass spectrometer. The identity of the ions was confirmed by comparison with the calculated isotope patterns, which also assisted in the choice of the adequate precursor ion to avoid coincidental mass overlaps of isobaric species in the mass-selected ion beam. ${ }^{35}$ Here, we selected $\left[{ }^{64} \mathrm{Zn}(\mathrm{OH})\right]^{+}$as the reactant ions by means of $\mathrm{Q}(1)$. In the hexapole, the ion/molecule reactions with $\mathrm{CH}_{4}, \mathrm{C}_{2} \mathrm{H}_{6}, \mathrm{C}_{2} \mathrm{D}_{6}, \mathrm{C}_{3} \mathrm{H}_{8}$, $\mathrm{C}_{3} \mathrm{D}_{8}, \mathrm{CD}_{3} \mathrm{CH}_{2} \mathrm{CD}_{3}$, and $\mathrm{CH}_{3} \mathrm{CD}_{2} \mathrm{CH}_{3}$ were probed at a collision energy $\left(E_{\text {lab }}\right)$ set to nominally $0 \mathrm{eV}$; this, in conjunction with the kinetic energy width of about $0.4 \mathrm{eV}$ of the parent ion at peak half-height, allowed the investigation of quasi-thermal reactions, as demonstrated previously. ${ }^{18}$

Since absolute rate constants cannot readily be determined by using the experimental setup of the VG BIO-Q mass spectrometer, the rate constant and the branching ratios of the reaction of $[\mathrm{Zn}(\mathrm{OH})]^{+}$with $\mathrm{C}_{3} \mathrm{H}_{8}$ have been determined by using a Spectrospin CMS 47X Fourier Transform Ion Cyclotron Resonance (FT-ICR) mass spectrometer; details of the instrument have been described previously. ${ }^{36,37}$ Atomic $[\mathrm{Zn}]^{+}$ions were generated by laser ablation of pure Zn metal disks using a Nd:YAG laser operating at $1064 \mathrm{~nm}$ in the presence of helium carrier gas. The $\left[{ }^{64} \mathrm{Zn}\right]^{+}$isotope was isolated and allowed to react with a mixture of $\mathrm{N}_{2} \mathrm{O}$ and $\mathrm{H}_{2} \mathrm{O}$ (ca. $5: 1)$ to give $\left[{ }^{64} \mathrm{Zn}(\mathrm{OH})\right]^{+}$. The so-formed product ions are subsequently quenched by collisional thermalization with the buffer gas (argon, ca. $2 \times 10^{-8} \mathrm{mbar}$ ). After collisional thermalization, the $\left[{ }^{64} \mathrm{Zn}(\mathrm{OH})\right]^{+}$species were mass-selected and exposed to react with $\mathrm{C}_{3} \mathrm{H}_{8}$ by introducing the substrate through a leak-valve. For the thermalized ions a temperature of $298 \mathrm{~K}$ was assumed. ${ }^{36,37}$ The branching ratios have been determined by extrapolating the ratios at different reaction times to $t=0 \mathrm{~s}$. Note, that somehow different branching ratios are obtained by using the two types of mass spectrometers applied in this study, $c f$. Fig. 1a (branching ratios of reactions (a), (b) and (c) are 78\%, 12\% and 10\%) and eqn (a)-(c); these differences may reflect the lack of proper collisional

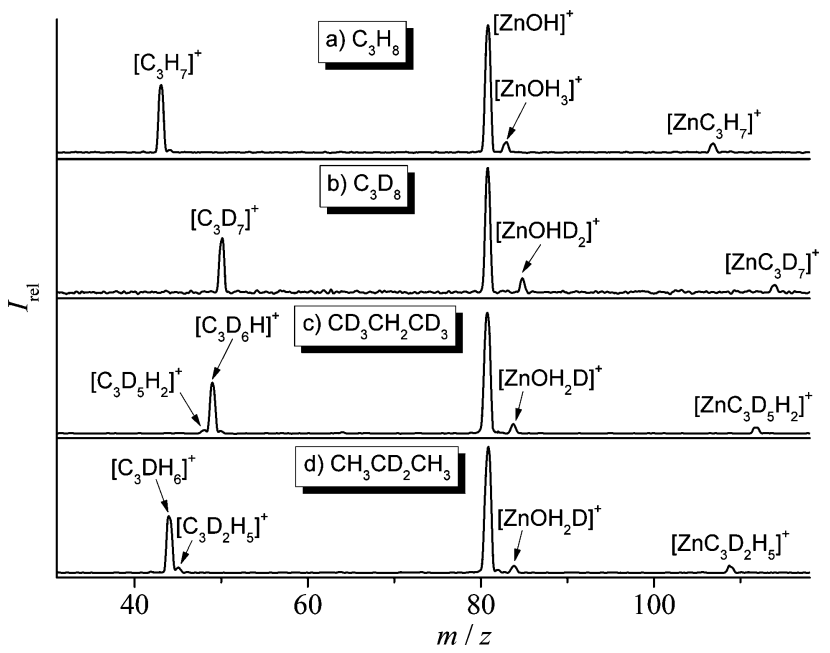

Fig. 1 Mass spectra showing the ion/molecule reactions of mass-selected $\left.{ }^{64} \mathrm{Zn}(\mathrm{OH})\right]^{+}$with $\mathrm{C}_{3} \mathrm{H}_{8}(\mathrm{a}), \mathrm{C}_{3} \mathrm{D}_{8}$ (b), $\mathrm{CD}_{3} \mathrm{CH}_{2} \mathrm{CD}_{3}$ (c), and $\mathrm{CH}_{3} \mathrm{CD}_{2} \mathrm{CH}_{3}$ (d) at a pressure of $1.0 \times 10^{-3} \mathrm{mbar}$ in the $\mathrm{VG}$ BIO-Q mass spectrometer.

thermalization in the experiments using the VG BIO-Q mass spectrometer.

Calculations were carried out by using the Gaussian 09 program suite. ${ }^{38}$ Potential energy surfaces (PESs) are calculated by using the Møller-Plesset second-order perturbation MP2 method $^{39,40}$ employing a triple-zeta level basis set with diffuse and polarization functions $6-311++\mathrm{G}(2 \mathrm{~d}, 2 \mathrm{p})$ for all atoms. ${ }^{41}$ To obtain even more accurate energies of the relevant structures, the coupled-cluster $\operatorname{CCSD}(\mathrm{T})$ method $^{42,43}$ with single, double, and perturbative treatment of triple excitations in conjunction with the correlation-consistent polarized valence triple-zeta basis sets cc-pVTZ was used. ${ }^{44,45}$ The MP2/6-311++G(2d,2p) optimized geometries were employed for the single-point coupled cluster calculations without reoptimization at the $\operatorname{CCSD}(\mathrm{T}) / \mathrm{cc}-\mathrm{pVTZ}$ levels, and the results are in line with the MP2 calculations (Table 1). All geometries were fully optimized without symmetry constraints. Vibrational frequency calculations were performed to identify the nature of reaction intermediates, transition states (TSs) and products. To corroborate which minima are linked by the considered transition states, normal coordinate analyses were performed on these TS structures by intrinsic reaction coordinate (IRC) routes in both reactant and product directions. ${ }^{46-48}$ Additional geometry optimizations starting from the last IRC structures were carried out when the IRC calculations did not converge. Unscaled vibrational frequencies were used to calculate zero-point energy (ZPE) corrections. To demonstrate the applicability of the MP2 method selected for this study, test calculations were performed at the MP2/6-311++G(2d,2p) level of theory (Table S1, ESI;); the results are in agreement, within $0.36 \mathrm{eV}$, of experimental values. $^{21,22,49}$

The relative energies of P1 and TS3/4 in Fig. 2 have also been calculated by DFT using different functionals ${ }^{50-59}$ and the $6-311++\mathrm{G}(2 \mathrm{~d}, 2 \mathrm{p})$ basis set, as well as by single-point energy calculations using the $\operatorname{CCSD}(\mathrm{T})$ method; the results are listed in Table S2 (ESI $\$$ ). MP2 calculated relative energies of high-spin and low-spin products of the reaction of $[\mathrm{Zn}(\mathrm{OH})]^{+}$with $\mathrm{C}_{3} \mathrm{H}_{8}, \mathrm{C}_{2} \mathrm{H}_{6}$, 
Table 1 The relative energies (in $\mathrm{eV}$ ) of intermediates, transition states and products obtained by MP2/6-311++G(2d,2p) and CCSD $(T) / c c-p V T Z$ (relative to separated $\mathrm{C}_{3} \mathrm{H}_{8}$ and $[\mathrm{Zn}(\mathrm{OH})]^{+}$)

\begin{tabular}{llllllllll}
\hline Path 1 & I1 & TS1/2 & I2 & P1 & I3 & TS3/4 & I4 & P2 \\
\hline MP2 & -1.70 & -0.38 & -0.39 & -0.20 & -1.70 & -0.40 & -1.78 & -1.12 \\
CCSD(T) & -1.65 & -0.31 & -0.32 & -0.13 & -1.65 & -0.38 & -1.62 & -1.19 \\
\hline TS4/5 & I5 & P3 & Path 2 & I6 & P4 & I7 & TS7/8 & I8 \\
\hline-1.70 & -2.22 & -1.23 & MP2 & -1.64 & 0.06 & -1.82 & -0.12 & -2.61 \\
-1.75 & -2.23 & -1.12 & CCSD(T) & -1.58 & 0.19 & -1.80 & -0.17 & -2.51 \\
\hline P5 & Path 3 & I9 & TS9/10 & I10 & P6 & TS1 & TS2 \\
\hline-1.07 & MP2 & -0.17 & 0.16 & -0.16 & 0.06 & 0.16 & 0.30 \\
-0.89 & CCSD(T) & -0.17 & 0.06 & -0.07 & 0.08 & 0.18 & 0.20
\end{tabular}

and $\mathrm{CH}_{4}$, respectively, are shown in Tables S3-S5 (ESI‡) with respect to the particular ground state separated reactant pair.

\section{Results and discussion}

In the thermal reaction of $[\mathrm{Zn}(\mathrm{OH})]^{+}$with propane (Fig. 1a), the generation of $\left[\mathrm{C}_{3} \mathrm{H}_{7}\right]^{+}$by hydride transfer ${ }^{60-64}$ corresponds to the main process (reaction (a)); in competition, one observes oxidative dehydrogenation, (reaction (b)) as well as the generation of $\left[\mathrm{Zn}\left(\mathrm{C}_{3}, \mathrm{H}_{7}\right)\right]^{+}$accompanied by the elimination of water (reaction (c)). The reaction pathways are confirmed in labeling experiments in which $\mathrm{C}_{3} \mathrm{D}_{8}, \mathrm{CD}_{3} \mathrm{CH}_{2} \mathrm{CD}_{3}$, and $\mathrm{CH}_{3} \mathrm{CD}_{2} \mathrm{CH}_{3}$ have been employed as substrates (Fig. 1b-d). The structural assignments of the neutral and/or cationic products described in eqn (a) to (c) are based on theoretical results (see below). The labeling experiments are quite instructive regarding the reaction mechanisms: (i) in the hydride transfer reaction, a secondary $\mathrm{C}-\mathrm{H}$ bond is preferentially activated. A best fit with the data obtained in Fig. 1 is obtained by assuming an average kinetic isotope effect (KIE) of 1.1 and a specificity of $1: 45$ in favor of the activation of a secondary $\mathrm{C}-\mathrm{H}$ bond of propane. ${ }^{64} \mathrm{In}$ contrast, it is the primary $\mathrm{C}-\mathrm{H}$ bond of $\mathrm{C}_{3} \mathrm{H}_{8}$ which exclusively ends up as water in reaction (c). At the detection limit, only $\left[\mathrm{Zn}\left(\mathrm{C}_{3} \mathrm{D}_{5} \mathrm{H}_{2}\right)\right]^{+}$ and $\left[\mathrm{Zn}\left(\mathrm{C}_{3} \mathrm{H}_{5} \mathrm{D}_{2}\right)\right]^{+}$are formed in the ion/molecule reactions with $\mathrm{CD}_{3} \mathrm{CH}_{2} \mathrm{CD}_{3}$ and $\mathrm{CH}_{3} \mathrm{CD}_{2} \mathrm{CH}_{3}$, respectively. Thus, both hydrogentransfer processes, i.e. reactions (a) and (c), do not share a common intermediate like $\left[\mathrm{Zn}\left(\mathrm{H}_{2} \mathrm{O}\right)\left(\mathrm{C}_{3} \mathrm{H}_{7}\right)\right]^{+}$as might be anticipated. Also, based on the labeling experiments, $\mathrm{ODH}$ proceeds via a specific transfer of $\mathrm{HD}$ in the reactions of $[\mathrm{Zn}(\mathrm{OH})]^{+}$with $\mathrm{CD}_{3} \mathrm{CH}_{2} \mathrm{CD}_{3}$ and $\mathrm{CH}_{3} \mathrm{CD}_{2} \mathrm{CH}_{3}$, respectively. Finally, the branching ratios given in eqn (a)-(c) as well as the rate constant $k\left([\mathrm{Zn}(\mathrm{OH})]^{+} / \mathrm{C}_{3} \mathrm{H}_{8}\right)$ of $3.2 \times$ $10^{-8} \mathrm{~cm}^{3} \mathrm{~s}^{-1}$ molecule ${ }^{-1}$ have been measured by using the FT-ICR mass spectrometer; the rate constant corresponds to an efficiency of $30 \%$, relative to the collision rate. ${ }^{65,66}$

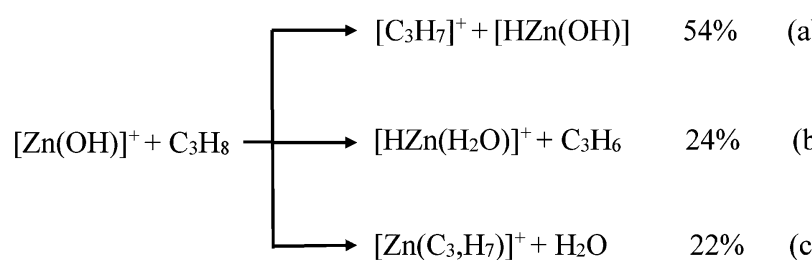

To obtain additional insight in the mechanisms of the reactions of $[\mathrm{Zn}(\mathrm{OH})]^{+}$with $\mathrm{C}_{3} \mathrm{H}_{8}, \mathrm{MP} 2 / 6-311++\mathrm{G}(2 \mathrm{~d}, 2 \mathrm{p})$ calculations have been performed, and the corresponding PESs are shown in Fig. 2 and Fig. S1 (ESI+). Overall, these reactions are controlled by the Lewis-acid character of the metal center interacting with the electron donating $\mathrm{C}-\mathrm{H}$ bonds of propane. Some pertinent details of the most favorable PESs are shown in Fig. 2a and b; possible pathways which involve the $\mathrm{OH}$ moiety interacting with $\mathrm{C}-\mathrm{H}$ bonds of propane have also been tested (Fig. 2c) but turned out to be higher in energy. Four different encounter complexes have been located on the PES for the initial interaction of the metal center with $\mathrm{C}-\mathrm{H}$ bonds of $\mathrm{C}_{3} \mathrm{H}_{8}$. In the iso-energetic I1 and I3, the metal interacts with two hydrogen atoms of the secondary position, and $\mathrm{H}-\mathrm{Zn}$ bond lengths amount to $187 / 185 \mathrm{pm}$ for I1 and $193 \mathrm{pm}$ for I2, respectively. In I6 two hydrogens from one methyl group participate while in $\mathrm{I}$, one $\mathrm{C}-\mathrm{H}$ bond of each of the two methyl groups is involved. All four intermediates form remarkably stable ion/molecule complexes $\left[\mathrm{Zn}(\mathrm{OH})\left(\mathrm{C}_{3} \mathrm{H}_{8}\right)\right]^{+}$, and these complexes profit from the electron donation from the $\mathrm{C}-\mathrm{H}$ bonds into the empty $4 \mathrm{~s}-4 \mathrm{p}$ hybrid orbital of zinc (see also below). These interactions are indicated by the fact that the coordinating $\mathrm{C}-\mathrm{H}$ bonds are slightly elongated (from $109 \mathrm{pm}$ in free propane to $112 \mathrm{pm}$ in I1 and I3, and to $110-111 \mathrm{pm}$ in I6 and in I7, respectively). Regarding the hydride transfer from a methyl group in intermediate $\mathrm{I} 6$ to the $\mathrm{Zn}$ atom, no barrier has been located in this step I6 $\rightarrow \mathrm{P} 4\left(\left[n-\mathrm{C}_{3} \mathrm{H}_{7}\right]^{+} /[\mathrm{HZn}(\mathrm{OH})]\right)$; in contrast, the hydride transfer from I1 to P1 $\left(\left[\mathrm{i}-\mathrm{C}_{3} \mathrm{H}_{7}\right]^{+} /\right.$ $[\mathrm{HZn}(\mathrm{OH})])$ proceeds via transition structure TS1/2 and intermediate I2. However, TS1/2 and I2 are almost iso-energetic, i.e. this pathway proceeds in a quasi barrier-free process. Notably, while the formation of product P1 is exothermic $(-0.20 \mathrm{eV})$ and thus accessible under thermal conditions, product $\mathrm{P} 4$ is much higher in energy $(0.06 \mathrm{eV})$; this is in line with the labeling experiments clearly favoring the former reaction (see above). As shown in Fig. S1a (ESI + , formation of $\left[\mathrm{i}-\mathrm{C}_{3} \mathrm{H}_{7}\right]^{+}$is also accessible via the more complex pathway $\mathrm{R} \rightarrow \mathrm{I} 1^{\prime} \rightarrow \mathrm{TS}^{\prime} / 2^{\prime} \rightarrow \mathrm{I} 2^{\prime} \rightarrow \mathrm{P} 1$. In the formation of $\left[\mathrm{i}-\mathrm{C}_{3} \mathrm{H}_{7}\right]^{+}$(Fig. 2a and Fig. S1a, ESI is co-generated; the alternative to produce a neutral water complex $\mathrm{Zn}\left(\mathrm{H}_{2} \mathrm{O}\right)$ is less favorable both kinetically and thermodynamically (product P6 of path 3, Fig. 2c). Likewise, the combined formation of $\mathrm{Zn}\left(\mathrm{H}_{2} \mathrm{O}\right)$ and $\left[n-\mathrm{C}_{3} \mathrm{H}_{7}\right]^{+}$is more endothermic than generating $\mathrm{HZn}(\mathrm{OH})$ and $\left[n-\mathrm{C}_{3} \mathrm{H}_{7}\right]^{+}$; the former product pair is $0.30 \mathrm{eV}$ above the entrance channel (P8, Fig. S1c, ESI\$). Thus, the interaction of the $\mathrm{OH}$ group of $[\mathrm{Zn}(\mathrm{OH})]^{+}$to $\mathrm{C}-\mathrm{H}$ bonds of $\mathrm{C}_{3} \mathrm{H}_{8}$ (Fig. $2 \mathrm{c}$ and Fig. S1c, ESI, $\$$ respectively) to form neutral $\left.\mathrm{Zn}_{(} \mathrm{H}_{2} \mathrm{O}\right)$ cannot compete with the initial coordination of the metal center to secondary or primary C-H bonds of propane, respectively (Fig. 2a and $b)$. These findings are also confirmed in single point energy calculations using the $\operatorname{CCSD}(\mathrm{T})$ method.

For the regiospecific ODH process, the sequence $\mathrm{I} 3 \rightarrow \mathrm{TS} 3 / 4 \rightarrow$ I4 $\rightarrow$ P2 (Fig. 2a) constitutes the energetically most favorable pathway. Formation of propene takes place via TS3/4, in which neutral $\mathrm{HZn}(\mathrm{OH})$ interacts with $\left[\mathrm{i}-\mathrm{C}_{3} \mathrm{H}_{7}\right]^{+}$resulting in intermediate I4; the NBO atomic charge of the $\mathrm{HZn}(\mathrm{OH})$ moiety in $\mathrm{TS} 3 / 4$ corresponds to $0.06|e|$, and the associated IRC paths are shown 


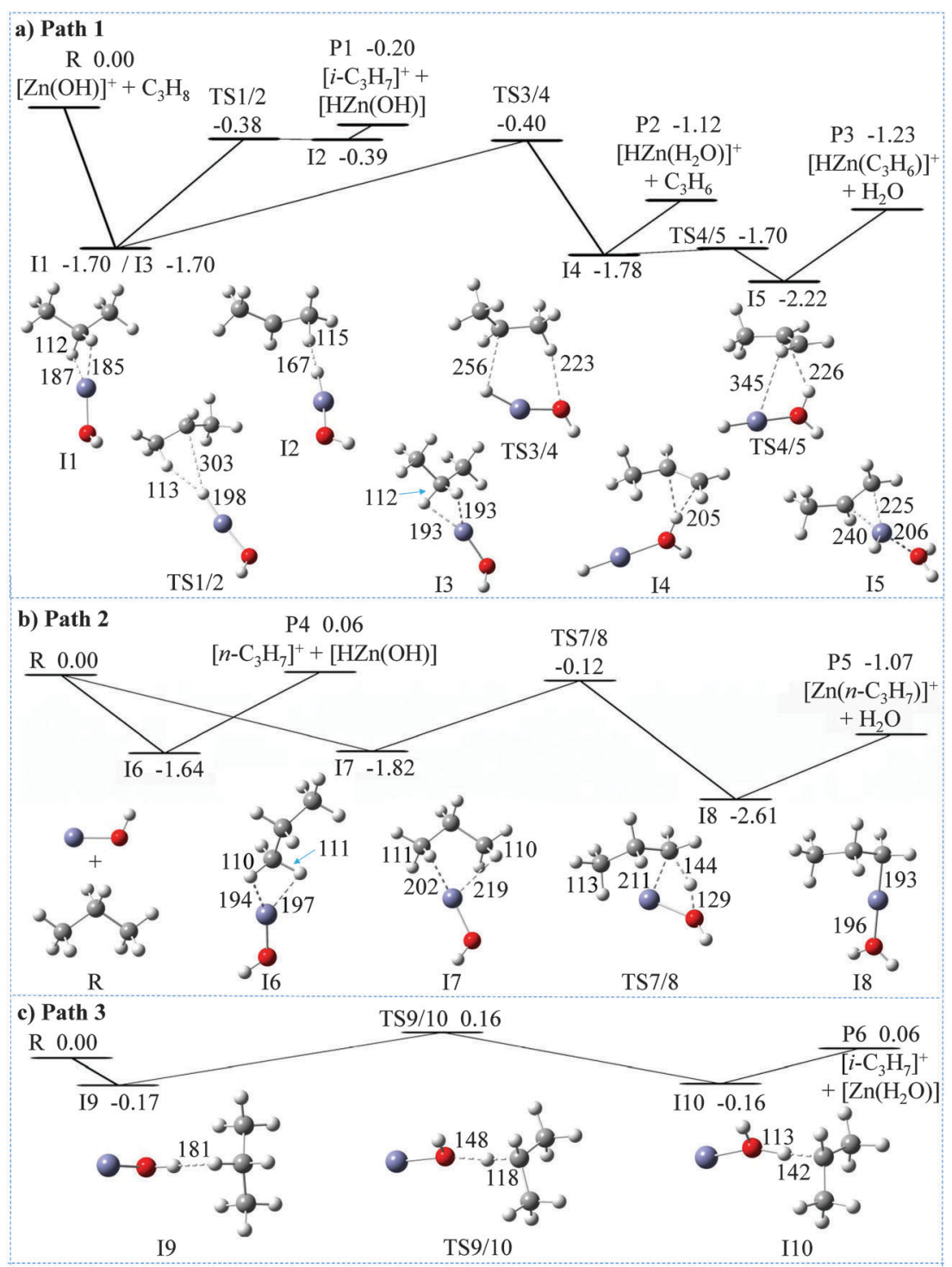

Fig. 2 MP2-calculated potential-energy profiles for the reactions of $[\mathrm{Zn}(\mathrm{OH})]^{+}$with $\mathrm{C}_{3} \mathrm{H}_{8}$. (a) Path 1 and (b) path 2 show the channels starting with the initial coordination of a secondary and primary $\mathrm{C}-\mathrm{H}$ bond of $\mathrm{C}_{3} \mathrm{H}_{8}$, to the $\mathrm{Zn}$ site; (c) path 3 depicts the channel starting with $\mathrm{C}-\mathrm{H}$ bond activation by the $\mathrm{OH}$ ligand. Color code: blue $\mathrm{Zn}$, red $\mathrm{O}$, gray $\mathrm{C}$, and white $\mathrm{H}$. Selected bond lengths are given in pm; relative $\Delta H_{\mathrm{OK}}$ energies (in eV) are given with reference to the separated reactant pair.

in Fig. S2 (ESI ). The weakly bound propene ligand in I4 can easily be liberated to yield the experimentally observed ODH product $\left[\mathrm{HZn}\left(\mathrm{H}_{2} \mathrm{O}\right)\right]^{+}(\mathrm{P} 2)$. In competition, I5 is generated in which the $\mathrm{Zn}$ atom is coordinated to the $\mathrm{C}=\mathrm{C}$ double bond of $\mathrm{C}_{3} \mathrm{H}_{6}$. The weaklybound $\mathrm{H}_{2} \mathrm{O}$ group can be eliminated yielding the cationic product $\left[\mathrm{HZn}\left(\mathrm{CH}_{3} \mathrm{CH}=\mathrm{CH}_{2}\right)\right]^{+}(\mathrm{P} 3)$, which is experimentally observed in reaction (c). A kinetically less favorable pathway for the elimination of water and formation of $\left[\mathrm{Zn}\left(n-\mathrm{C}_{3} \mathrm{H}_{7}\right)\right]^{+}$of reaction (c) is shown in Fig. $2 \mathrm{~b}$ (see below). The energetic requirement to produce P2 and P3 are comparable $(-1.12$ versus $-1.23 \mathrm{eV})$; this is consistent with similar branching ratio of reactions (b) and (c) as observed experimentally. As to the energetics of the competitive productions of $\mathrm{P} 1$ versus $\mathrm{P} 2$ and $\mathrm{P} 3$, the relative energy of $\mathrm{P} 1(-0.20 \mathrm{eV})$ is higher than that of TS3/4 $(-0.40 \mathrm{eV})$. The same order of relative energies of
P1 and TS3/4 are also obtained by DFT calculations using different functionals as well as single point energy calculations using the CCSD(T) method (see Table S2, ESI $\ddagger$ ). Taking into account the errors as well as previous work, ${ }^{67-69}$ our calculations are in agreement with the branching ratio of the production of $\left[\mathrm{i}-\mathrm{C}_{3} \mathrm{H}_{7}\right]^{+} /[\mathrm{HZn}(\mathrm{OH})]$ (reaction (a)) versus reactions (b) and (c) (ca. $54 \%: 46 \%$ by using the FT-ICR mass spectrometer). In addition, the direct dissociation $\mathrm{I} 1 \rightarrow \mathrm{P} 1$ is kinetically favored over a more complex rearrangement/dissociation path proceeding via the tight transition state TS3/4.

For the alternative water formation pathway of reaction (c), as shown in Fig. $2 \mathrm{~b}$, the generation of $\left[\mathrm{Zn}\left(n-\mathrm{C}_{3} \mathrm{H}_{7}\right)\right]^{+}$occurs along the route $\mathrm{I} 7 \rightarrow \mathrm{TS} 7 / 8 \rightarrow \mathrm{I} 8 \rightarrow \mathrm{P} 5$ with the intermediate formation of a propyl-water complex I8, $\left[\mathrm{Zn}\left(\mathrm{C}_{3} \mathrm{H}_{7}\right)\left(\mathrm{H}_{2} \mathrm{O}\right)\right]^{+}$; 


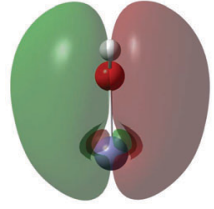

a) $\mathrm{HOMO}$ of $[\mathrm{Zn}(\mathrm{OH})]^{+}$

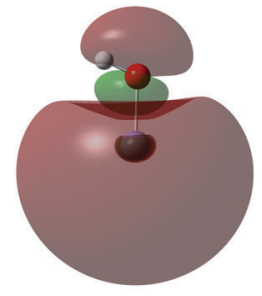

b) LUMO of $[\mathrm{Zn}(\mathrm{OH})]^{+}$

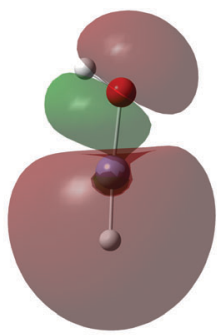

c) $\mathrm{HOMO}$ of $[\mathrm{HZn}(\mathrm{OH})]$
Fig. $3 \mathrm{HOMO}$ (a) and LUMO (b) of $[\mathrm{Zn}(\mathrm{OH})]^{+}$, and $\mathrm{HOMO}$ (c) of neutral $[\mathrm{HZn}(\mathrm{OH})]$.

mechanistically, this is a $\sigma$ bond metathesis reaction. The relative energy of TS7/8 amounts to $-0.12 \mathrm{eV}$, which is higher in energy as compared to TS3/4 $(-0.40 \mathrm{eV})$, and thus unlikely to compete efficiently under thermal conditions. A brief comparison of structural features of the transition states for the $\sigma$-metathesis reaction, i.e. TS7/8 versus TS1 (Fig. S1b, ESI $\$$ ) is indicated. In TS7/8, the metal center is not only a constituent of the four-membered ring which is essential for a $\sigma$-bond metathesis but is also coordinated by a $\mathrm{C}-\mathrm{H}$ bond of the distal methyl group of propane; this results in a slight but clearly discernible elongation of the $\mathrm{C}-\mathrm{H}$ bond from $109 \mathrm{pm}$ to $113 \mathrm{pm}$. Quite likely, this agostic interaction is beneficial for the stabilization of TS7/8 versus TS1; the latter one lacks this stabilization.

Finally, with regard to the $\mathrm{C}-\mathrm{H}$ bond activation in $[\mathrm{Zn}(\mathrm{OH})]^{+}$, the $4 \mathrm{~s}$ orbital hybridizes with a $4 \mathrm{p}$ orbital of $\mathrm{Zn}$ leading to the highest occupied molecular orbital (HOMO) and the lowest unoccupied molecular orbital (LUMO), respectively (Fig. 3a and b). While the former is used to bind to the $\mathrm{OH}$ ligand, the latter can accept two electrons from a $\mathrm{C}-\mathrm{H}$ bond of propane resulting in hydride transfer and carbocation formation; this view is supported by the similarity of the HOMO of neutral $[\mathrm{HZn}(\mathrm{OH})]$ with the LUMO of $[\mathrm{Zn}(\mathrm{OH})]^{+}$(Fig. $3 \mathrm{~b}$ and $\mathrm{c}$ ).

On the triplet PES, all reaction channels described above for the $[\mathrm{Zn}(\mathrm{OH})]^{+}-\mathrm{C}_{3} \mathrm{H}_{8}$ system have been calculated to be endothermic (Table S3, ESI $\ddagger$ ); therefore, this spin state has not been considered in further calculations. ${ }^{70,71}$

As mentioned above, the reactions of $[\mathrm{Zn}(\mathrm{OH})]^{+}$with ethane and methane have also been studied in the experiments; here, only adduct formations are observed for $[\mathrm{Zn}(\mathrm{OH})]^{+}-\mathrm{C}_{2} \mathrm{H}_{6}$ (Fig. S3, ESI $\$)$. In agreement with these findings, all reactions involving $\mathrm{C}-\mathrm{H}$ bond activation for the $[\mathrm{Zn}(\mathrm{OH})]^{+}-\mathrm{C}_{2} \mathrm{H}_{6}$ and $[\mathrm{Zn}(\mathrm{OH})]^{+}-\mathrm{CH}_{4}$ systems are endothermic according to MP2 calculations (see Tables S4 and S5, ESI $\$$ ).

With regard to catalysis, $[\mathrm{Zn}(\mathrm{OH})]^{+}$species have been conjectured to play a role in $\mathrm{Zn} / \mathrm{Na}$-ZSM5 catalysts for the conversion of propane to propene and aromatic compounds. ${ }^{14,72-75}$ As shown in this study, the metal $\mathrm{Zn}$ and the resulting strong Lewis-acid character in $[\mathrm{Zn}(\mathrm{OH})]^{+}$are of crucial importance for the hydride transfer from propane to generate both $\left[\mathrm{i}-\mathrm{C}_{3} \mathrm{H}_{7}\right]^{+}$ and propene. ${ }^{72,74}$ Thus, the identification of the active sites of $\mathrm{ZnOH}$ species helps to unravel part of the enigma associated with the conversion of alkane by zinc catalysts. ${ }^{72-75}$

\section{Conclusion}

Here, we report and analyze the thermal gas-phase reactions of $[\mathrm{Zn}(\mathrm{OH})]^{+}$with $\mathrm{C}_{3} \mathrm{H}_{8}$ by using experimental and theoretical methods. The reactivity of cationic zinc hydroxide $[\mathrm{Zn}(\mathrm{OH})]^{+}$toward $\mathrm{C}_{3} \mathrm{H}_{8}$ is characterized by $\mathrm{C}-\mathrm{H}$ bond activation; the main reaction channel corresponds to a hydride transfer from the hydrocarbon to the Lewis acid metal center resulting in the generation of $[\mathrm{HZn}(\mathrm{OH})] /$ $\left[\mathrm{i}-\mathrm{C}_{3} \mathrm{H}_{7}\right]^{+}$. Homolytic $\mathrm{C}-\mathrm{H}$ bond activation give rise to an $\mathrm{ODH}$ channel (generation of propene) as well as the competitive formation of $\left[\mathrm{HZn}\left(\mathrm{CH}_{3} \mathrm{CH}=\mathrm{CH}_{2}\right)\right]^{+} / \mathrm{H}_{2} \mathrm{O}$. Our study may prove helpful to further understand the industrially relevant, catalytic conversion of small alkanes by $\mathrm{Zn}$ species.

\section{Acknowledgements}

This work is supported by the Fonds der Chemischen Industrie, the Deutsche Forschungsgemeinschaft (DFG), and the Cluster of Excellence "Unifying Concepts in Catalysis" (coordinated by the Technische Universität Berlin and funded by the DFG). For computational resources, the Institut für Mathematik at the Technische Universität Berlin is acknowledged. Dr Xiaonan Wu is grateful to the Alexander von Humboldt-Stiftung for a postdoctoral fellowship. We thank Dr Robert Kretschmer, Dr Patricio A. González-Navarrete, Dr Shiya Tang, Dr Shaodong Zhou, and Dr Nicole Rijs for helpful suggestions and discussions. Andrea Beck is to be thanked for technical assistance, and the Reviewer for thoughtful comments.

\section{References}

1 C. Coperet, Chem. Rev., 2010, 110, 656.

2 A. Sattler and G. Parkin, Nature, 2010, 463, 523.

3 J. Roithová and D. Schröder, Chem. Rev., 2010, 110, 1170.

4 D. Balcells, E. Clot and O. Eisenstein, Chem. Rev., 2010, 110, 749.

5 K. Eller and H. Schwarz, Chem. Rev., 1991, 91, 1121.

6 A. D. Ryabov, Chem. Rev., 1990, 90, 403.

7 A. W. Castleman, Jr., Catal. Lett., 2011, 141, 1243.

8 X.-L. Ding, X.-N. Wu, Y.-X. Zhao and S.-G. He, Acc. Chem. Res., 2012, 45, 382.

9 S. Arndt, B. Uysal, A. Berthold, T. Otrebma, Y. Aksu, M. Driess and R. Schomäcker, J. Nat. Gas Chem., 2012, 21, 581.

10 E. A. Pidko and R. A. van Santen, J. Phys. Chem. C, 2007, 111, 2643.

11 M. V. Frash and R. A. van Santen, Phys. Chem. Chem. Phys., 2000, 2, 1085.

12 S. M. Almutairi, B. Mezari, P. C. Magusin, E. A. Pidko and E. J. Hensen, ACS Catal., 2011, 2, 71.

13 S. Arndt, Y. Aksu, M. Driess and R. Schomacker, Catal. Lett., 2009, 131, 258.

14 H. Berndt, G. Lietz and J. Volter, Appl. Catal., A, 1996, 146, 365.

15 J. Heemsoth, E. Tegeler, F. Roessner and A. Hagen, Microporous Mesoporous Mater., 2001, 46, 185. 
16 D. Schröder, H. Schwarz, S. Polarz and M. Driess, Phys. Chem. Chem. Phys., 2005, 7, 1049.

17 R. Kretschmer, M. Schlangen and H. Schwarz, ChemPlusChem, 2013, 78, 952.

18 D. Schröder, H. Schwarz, S. Schenk and E. Anders, Angew. Chem., Int. Ed., 2003, 42, 5087.

19 C. Bergquist, T. Fillebeen, M. M. Morlok and G. Parkin, J. Am. Chem. Soc., 2003, 125, 6189.

20 C. R. A. Catlow, S. T. Bromley, S. Hamad, M. Mora-Fonz, A. A. Sokol and S. M. Woodley, Phys. Chem. Chem. Phys., 2010, 12, 786.

21 L. N. Zack, M. Sun, M. P. Bucchino, D. J. Clouthier and L. M. Ziurys, J. Phys. Chem. A, 2012, 116, 1542.

22 I. Iordanov, K. D. D. Gunaratne, C. L. Harmon, J. O. Sofo and A. W. Castleman, Jr., J. Chem. Phys., 2012, 136, 214314.

23 M. A. Flory, A. J. Apponi, L. N. Zack and L. M. Ziurys, J. Am. Chem. Soc., 2010, 132, 17186.

24 R. Georgiadis and P. Armentrout, J. Am. Chem. Soc., 1986, 108, 2119.

25 Z. Su, S. Qin, D. Tang, H. Yang and C. Hu, J. Mol. Struct., 2006, 778, 41.

26 H. Schwarz, Acc. Chem. Res., 1989, 22, 282.

27 Z.-C. Wang, N. Dietl, R. Kretschmer, J.-B. Ma, T. Weiske, M. Schlangen and H. Schwarz, Angew. Chem., Int. Ed., 2012, 51, 3703.

28 N. Dietl, M. Schlangen and H. Schwarz, Angew. Chem., Int. Ed., 2012, 51, 5544.

29 X. N. Wu, X. N. Li, X. L. Ding and S. G. He, Angew. Chem., Int. Ed., 2013, 125, 2504.

30 J. B. Ma, B. Xu, J. H. Meng, X. N. Wu, X. L. Ding, X. N. Li and S. G. He, J. Am. Chem. Soc., 2013, 135, 2991.

31 G. E. Johnson, E. C. Tyo and A. W. Castleman, Jr., Proc. Natl. Acad. Sci. U. S. A., 2008, 105, 18108.

32 G. E. Johnson, R. Mitric, M. Nossler, E. C. Tyo, V. BonacicKoutecky and A. W. Castleman, Jr., J. Am. Chem. Soc., 2009, 131, 5460 .

33 A. Bozovic and D. K. Bohme, Phys. Chem. Chem. Phys., 2009, 11, 5940 .

34 C. Trage, D. Schröder and H. Schwarz, Chem. - Eur. J., 2005, 11, 619.

35 D. Schröder and H. Schwarz, Can. J. Chem., 2005, 83, 1936.

36 K. Eller and H. Schwarz, Int. J. Mass Spectrom. Ion Processes, 1989, 93, 243.

37 D. Schröder, H. Schwarz, D. E. Clemmer, Y. Chen, P. Armentrout, V. I. Baranov and D. K. Böhme, Int. J. Mass Spectrom. Ion Processes, 1997, 161, 175.

38 M. J. Frisch, G. W. Trucks, H. B. Schlegel, G. E. Scuseria, M. A. Robb, J. R. Cheeseman, G. Scalmani, V. Barone, B. Mennucci, G. A. Petersson, H. Nakatsuji, M. Caricato, X. Li, H. P. Hratchian, A. F. Izmaylov, J. Bloino, G. Zheng, J. L. Sonnenberg, M. Hada, M. Ehara, K. Toyota, R. Fukuda, J. Hasegawa, M. Ishida, T. Nakajima, Y. Honda, O. Kitao, H. Nakai, T. Vreven, J. A. Montgomery, Jr., J. E. Peralta, F. Ogliaro, M. Bearpark, J. J. Heyd, E. Brothers, K. N. Kudin, V. N. Staroverov, R. Kobayashi, J. Normand, K. Raghavachari, A. Rendell, J. C. Burant, S. S. Iyengar, J. Tomasi, M. Cossi, N. Rega, J. M. Millam, M. Klene, J. E. Knox, J. B. Cross, V. Bakken,
C. Adamo, J. Jaramillo, R. Gomperts, R. E. Stratmann, O. Yazyev, A. J. Austin, R. Cammi, C. Pomelli, J. W. Ochterski, R. L. Martin, K. Morokuma, V. G. Zakrzewski, G. A. Voth, P. Salvador, J. J. Dannenberg, S. Dapprich, A. D. Daniels, O. Farkas, J. B. Foresman, J. V. Ortiz, J. Cioslowski and D. J. Fox, Gaussian 09, Revision A.1 asasas, Gaussian, Inc., Wallingford CT, 2009.

39 H. B. Schlegel, J. Chem. Phys., 1986, 84, 4530.

40 J.-L. Li, C.-Y. Geng, X.-R. Huang and C.-C. Sun, J. Chem. Theory Comput., 2006, 2, 1551.

41 M. J. Frisch, J. A. Pople and J. S. Binkley, J. Chem. Phys., 1984, 80, 3265.

42 J. A. Pople, M. Headgordon and K. Raghavachari, J. Chem. Phys., 1987, 87, 5968.

43 G. D. Purvis and R. J. Bartlett, J. Chem. Phys., 1982, 76, 1910. 44 R. A. Kendall, T. H. Dunning and R. J. Harrison, J. Chem. Phys., 1992, 96, 6796.

45 T. H. Dunning, J. Chem. Phys., 1989, 90, 1007.

46 K. Fukui, Acc. Chem. Res., 1981, 14, 363.

47 C. Gonzalez and H. B. Schlegel, J. Phys. Chem., 1990, 94, 5523. 48 G. A. Natanson, B. C. Garrett, T. N. Truong, T. Joseph and

D. G. Truhlar, J. Chem. Phys., 1991, 94, 7875.

49 D. E. Clemmer, N. F. Dalleska and P. B. Armentrout, J. Chem. Phys., 1991, 95, 7263.

50 C. Lee, W. Yang and R. G. Parr, Phys. Rev. B: Condens. Matter Mater. Phys., 1988, 37, 785.

51 A. D. Becke, J. Chem. Phys., 1993, 98, 5648.

52 J. P. Perdew, K. Burke and M. Ernzerhof, Phys. Rev. Lett., 1996, 77, 3865.

53 A. D. Becke, J. Chem. Phys., 1993, 98, 1372.

54 Y. Zhao and D. G. Truhlar, Theor. Chem. Acc., 2008, 120, 215. 55 J. M. Tao, J. P. Perdew, V. N. Staroverov and G. E. Scuseria, Phys. Rev. Lett., 2003, 91, 146401.

56 A. D. Becke, Phys. Rev. A, 1988, 38, 3098.

57 C. Adamo and V. Barone, J. Chem. Phys., 1998, 108, 664.

58 S. Grimme, J. Chem. Phys., 2006, 124, 034108.

59 T. Schwabe and S. Grimme, Phys. Chem. Chem. Phys., 2006, 8, 4398.

60 X. Cai, Y. Li, E. R. O'Grady and J. A. Farrar, Int. J. Mass. Spectrom., 2005, 241, 271.

61 S. Feyel, D. Schröder and H. Schwarz, J. Phys. Chem. A, 2006, 110, 2647.

62 N. Dietl, M. Engeser and H. Schwarz, Chem. - Eur. J., 2009, 15, 11100.

63 D. Schröder, H. Florencio, W. Zummack and H. Schwarz, Helv. Chim. Acta, 1992, 75, 1792.

64 M. Schlangen, D. Schröder and H. Schwarz, Chem. - Eur. J., 2007, 13, 6810.

65 T. Su and M. Bowers, Int. J. Mass Spectrom. Ion Phys., 1973, $12,347$.

66 R. Wesendrup, D. Schröder and H. Schwarz, Angew. Chem., Int. Ed., 1994, 33, 1174.

67 D. Schröder and J. Roithova, Angew. Chem., Int. Ed., 2006, 45, 5705.

68 N. Dietl, C. van der Linde, M. Schlangen, M. K. Beyer and H. Schwarz, Angew. Chem., Int. Ed., 2011, 50, 4966. 
69 D. J. McAdoo, Mass. Spectrom. Rev., 1988, 7, 363.

70 J.-L. Li, C.-Y. Geng, X.-R. Huang and C.-C. Sun, Theor. Chem. Acc., 2007, 117, 417.

71 D. Schröder, S. Shaik and H. Schwarz, Acc. Chem. Res., 2000, 33, 139.

72 X.-L. Sun, X.-R. Huang, J.-L. Li, R.-P. Huo and C.-C. Sun, J. Phys. Chem. A, 2012, 116, 1475.
73 J. A. Biscardi and E. Iglesia, Phys. Chem. Chem. Phys., 1999, 1, 5753.

74 H. A. Aleksandrov and G. N. Vayssilov, Catal. Today, 2010, 152, 78.

75 H. A. Aleksandrov, E. A. I. Shor, A. M. Shor, V. A. Nasluzov, G. N. Vayssilov and N. Rosch, Soft Mater., 2012, 10, 216. 